\title{
Identification of artificial interspecific hybrids in the genus Elymus (Poaceae) by using ISSR- markers
}

\author{
Maria Emtseva*, and Alexander Agafonov \\ Central Siberian Botanical Garden CSBG, Zolotodolinskaya st., 101, Novosibirsk, Russia, 630090
}

\begin{abstract}
Reproductive relationships between species of the genus Elymus (Poaceae) from mixed populations of the Southern Urals were studied. The true hybrids were identified by using ISSR-markers in comparison with parental biotypes. The presence in the true hybrids of species-specific ISSR-bands from both parental forms is provided by high level of homozygosity of species in genus Elymus, as a result of predominant self-pollination.
\end{abstract}

\section{Introduction}

The genus Elymus L. consists of polyploid perennial species of the tribe Triticeae Dum. (Poaceae). Taxa of the genus have haplomes "St", "H", "Y", "P", "W", which originated from other genera of tribe Triticeae in different combinations, but "St" haplome presents in all Elymus species [1]. "St" haplome descended from Pseudoroegneria genus, " $\mathrm{H}$ " haplome - from Hordeum genus, "P" haplome - from Agropyron genus, "W" haplome - from Australopyrum Löve; the origination of "Y" haplome was not determined exactly yet. The genome constitution of E. mutabilis (Drob.) Tzvel. and E. caninus (L.) L. was identified as $\mathrm{StStHH}(2 \mathrm{n}=4 \mathrm{x}=28)$ [1]. In E. uralensis (Nevski) Tzvelev and E. viridiglumis (Nevski) Czer. the chromosome number $2 \mathrm{n}=28$ was determined too [2], but genome formula was not identified conclusively.

Previously by using six ISSR-primers we showed the existence of genetic distances between biotypes of E. uralensis, E. viridiglumis, E. mutabilis and E. caninus growing on the closely located areas of Southern Urals, and significant distinctions between groups of Ural and Siberian species were revealed (Fig. 1).

\footnotetext{
Corresponding author: emtsevamv@yandex.ru
} 


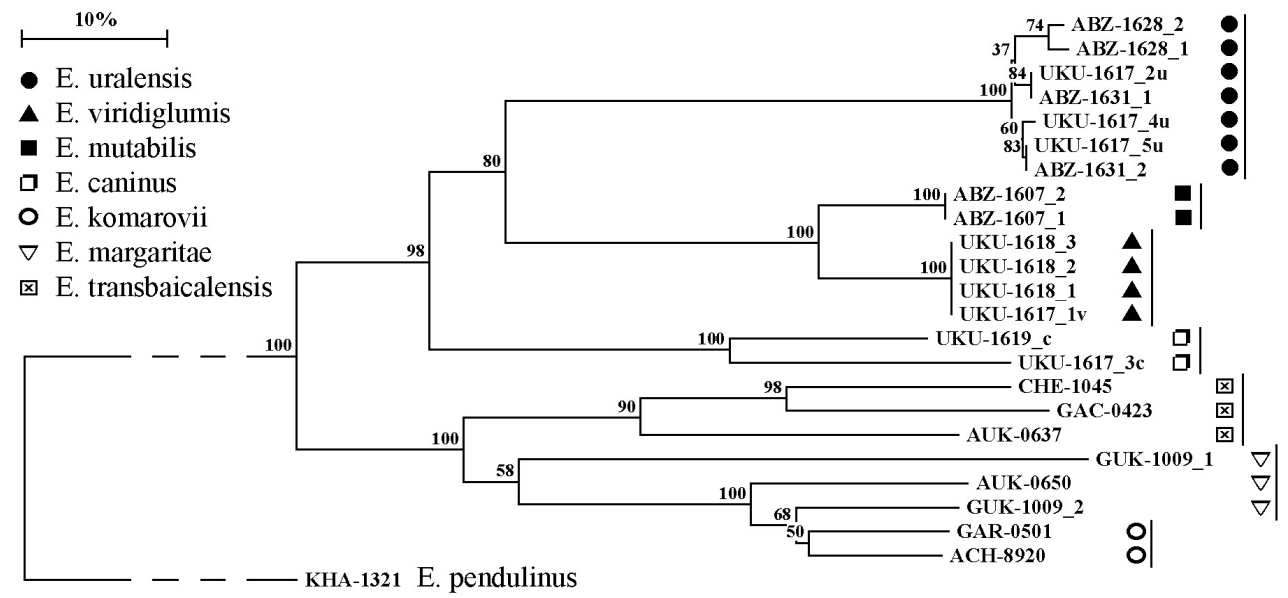

Fig. 1. Neighbour-Joining consensus tree with bootstrap support values based on results of the use of six ISSR-primers.

The multiple reticulate microevolution (which includes periodic hybridization and introgression), as a result of these species growing together during some generations, was suggested. For the study of reproductive compatibility of these species we created a series of hybrid plants between selective biotypes from mixed populations. The purpose of this work was identification of hybrid $\mathrm{F}_{1}$ plants between E. uralensis, E. viridiglumis, E. mutabilis and E. caninus based on their specificity on ISSR-markers.

\section{Materials and Methods}

$\mathrm{F}_{1}$ hybrids were created on the experimental plot of CSBG SB RAS (summer vegetation of 2017) by using the previously developed method [3]. These $F_{1}$ plants were grown in climate chamber of CSBG SB RAS. DNA was isolated from dried leaves by using kit for isolation of genomic DNA NucleoSpin Plant II (Macherey-Nagel, Germany). The PCR was set with ISSR-primers HB12 ((CAC) $\left.)_{3} \mathrm{GC}\right), \mathrm{M} 2\left((\mathrm{AC})_{8}(\mathrm{C} / \mathrm{T}) \mathrm{G}\right)$ and M11 $\left((\mathrm{CA})_{6}(\mathrm{G} / \mathrm{A})\right)$. The $15 \mu \mathrm{l}$ mix of PCR contained $10 \mathrm{mM}$ primer, $25 \mathrm{mM} \mathrm{MgCl} 2,5 \mathrm{mM}$ deoxynucleotides, 1x PCRbuffer, 0,9 units of Taq DNA polymerase and $2 \mu$ l of template DNA. PCR was carried out in C 1000 Thermal Cycler (BioRad Laboratories, USA). Annealing temperature for HB12 and $\mathrm{M} 11$ primers was $51^{\circ} \mathrm{C}$, for $\mathrm{M} 2$ primer $-56^{\circ} \mathrm{C}$. The obtained PCR-products were stained by SYBR-Green dye and separated by $1,5 \%$ agarose gel electrophoresis in $1 \mathrm{x}$ TBE buffer. The size of ISSR-fragments was determined according to $1 \mathrm{~kb}$ DNA ladder. Results of PCR were visualized by Gel Doc XR+ gel documentation system (BioRad Laboratories, USA).

\section{Results and Discussion}

We have obtained 20 plants in 7 cross combinations among E. uralensis, E. viridiglumis, E. mutabilis and E. caninus. Results of ISSR-analyses of assumed hybrids are shown in Fig. 2 in comparison with parental biotypes. 


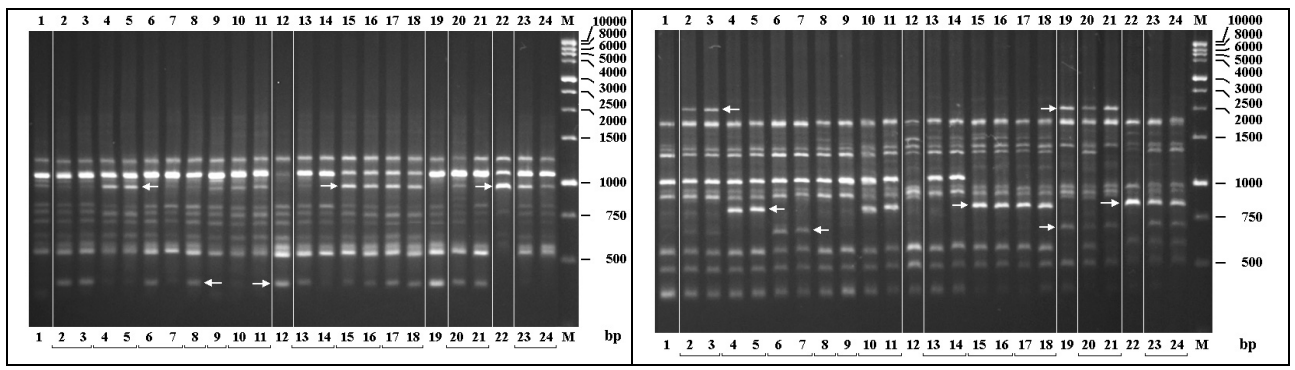

Fig. 2. ISSR-analysis of E. uralensis, E. viridiglumis, E. mutabilis and E. caninus and of hybrids between them with primers HB12 (left) and M11 (right). 1. E. uralensis UKU-1617-2u; 2, 3. uralen ABZ-1634 × mutab ABZ-1607; 4, 5. uralen UKU-1617-2u $\times$ canin UKU-1613; 6, 7. uralen UKU$1618 \times$ mutab ABZ-1665; 8. uralen UKU-1617-4u $\times$ viridi UKU-1618; 9. uralen ABZ-1631 $\times$ viridi UKU-1618; 10, 11. uralen UKU-1617-2 × canin UKU-1617-3c; 12. E. viridiglumis UKU-1618; 13, 14. viridi UKU-1618 $\times$ uralens ABZ-1634; 15-18. viridi UKU-1618 $\times$ canin UKU-1613; 19. E. mutabilis ABZ-1607; 20, 21. mutab ABZ-1607 $\times$ uralens ABZ-1634; 22. E. caninus UKU-1613; 23. canin UKU-1613 × mutab ABZ-1665; 24. canin ABZ-1654 × mutab ABZ-1665.

1. In the combination ural $\times$ mutab (Fig. 2, tracks 2, 3, 6, 7) 4 plants were obtained. With the use of M11 primer 2 of 4 plants had paternal 2000 b.p. band, and 2 other plants had paternal $\sim 700$ b.p. band (shown by arrows). Based on these results, we can conclude, that all 4 obtained plants are hybridous.

2. In the combination ural $\times$ canin (Fig. 2, tracks $4,5,10,11$ ) also 4 plants were obtained. With HB12 and M11 primers all 4 plants had fragments, specific for paternal form E. caninus, $\sim 900$ b.p. and $\sim 800$ b.p., respectively (shown by arrows). Hence, all 4 plants are hybridous.

3. In the combination ural $\times$ viridi (Fig. 2, tracks 8, 9) 2 plants were obtained. With M2 primer, the first plant had paternal $\sim 850$ b.p. band, and with HB12 primer it had paternal $\sim 200$ b.p. band (shown by arrows). With M11 primer both plants did not differ from the maternal form. We can conclude that the first plant is a hybrid, and the second one - is non-hybridous.

4. In the combination viridi $\times$ ural (Fig. 2, tracks 13, 14) all 2 obtained plants with primers HB12, M2 and M11 had amplicons, specific for paternal form E. uralensis, 1100 b.p., $\sim 600$ b.p. and $\sim 1200$ b.p., respectively, what verifies that they are hybridous.

5. In the combination viridi $\times$ canin (Fig. 2, tracks 15-18) all 4 obtained plants with primers HB12 and M11 had specific paternal bands 900 b.p. and 800 b.p., respectively. With M2 primer paternal band in all plants coincides in size with the maternal one, so plants did not differ from the maternal form, but we can surely say, that all 4 plants are hybridous.

6. In the combination mutab $\times$ ural (Fig. 2, tracks 20, 21) 2 plants were obtained. With M2 and M11 primers these plants do not differ from maternal forms and do not have specific paternal amplicons. With HB12 one plant had double 1000 b.p. fragment as in the maternal form, while the other plant does not have it. Based on a molecular data, we can assume that these plants are non-hybridous.

7. In the combination canin $\times$ mutab (Fig. 2, tracks 23,24 ) all 2 obtained plants with primers HB12 and M2 had specific paternal bands $~ 600$ b.p. and $\sim 850$ b.p., respectively. With M11 primer these plants had no clear paternal bands sized 2000 b.p., but they had paternal bands $\sim 700$ b.p. It all points that these plants are hybridous. 
We have obtained hybrid $\mathrm{F}_{1}$ plants in crosses of E. uralensis, E. viridiglumis, E. mutabilis and E. caninus in different combinations, except for the pair E. mutabilis $-E$. viridiglumis. The presence in hybrids of species-specific ISSR-bands from both parental forms is provided by high level of homozygosity of species in the genus Elymus, as a result of predominant self-pollination. Hence, the present study shows the possibility to determine the hybridity of plants at early ontogenesis stages by means of ISSR-markers. Subsequently, based on the results of the analysis of anthers condition and seed fertility of these hybrids, the conclusion will be drawn about the presence or absence of reproductive isolation and introgressive processes between species.

The work was carried out within the framework of the State Assignment of CSBG SB RAS "Assessment of morphogenetic potential of North Asian plant populations by experimental methods" (№ AAAA-A17-117012610051-5) with partial financial support of Russian Foundation for Basic Research (grant no. 18-04-01030). The publication was prepared with material of CSBG representing USU (United Specific Unit) “Collections of living plants indoors and outdoors”, USU № 440534.

\section{References}

1. D.R. Dewey, Gene manipulation in plant improvement (Springer, Boston, MA, 1984)

2. N.S. Probatova, V.Y. Barkalov, A.V. Agafonov, Scholary notes of Transbaikal State University. Series Biological Sciences, 12, 88-95 (2017) (in Russian)

3. A.V. Agafonov, Rus. J. Genetics, 40, 1229-1238 (2004) 